\title{
INTERACTIVE ONLINE PHYSICS LABS INCREASE HIGH SCHOOL STUDENTS' INTEREST
}

\author{
Patrick Gryczka $^{1}$ (D) Edward Klementowicz ${ }^{2}$ (D) Chappel Sharrock $^{3}(\mathbb{D})$, Jin Kim Montclare Kid $^{2,3}$ \\ ${ }^{1}$ Department of Computer Science and Engineering, New York University Tandon School of \\ Engineering (United States) \\ ${ }^{2}$ Department of Chemical and Biomolecular Engineering, New York University Tandon School of \\ Engineering (United States) \\ ${ }^{3}$ Department of Chemistry, New York University College of Arts and Science (United States) \\ pg1009@,nyu.edu, ewk235@,nyu.edu, cs3682@,nyu.edu, *montclare@nyu.edu
}

Received November 2015

Accepted March 2016

\section{Abstract}

Here we describe the incorporation of a web-based application focusing on circuits for the physics high school classroom as part of an outreach program. The program involves college mentors creating and implementing science lessons in collaboration with the classroom teacher. Focusing on the challenge of understanding circuit design, a technology rich module is employed to improve learning and motivation of the students. The students' conceptual understanding as well as interest in circuits was increased, the college mentors earned valuable teaching and mentoring experience and the teacher enjoyed more oneon-one time as well as assistance with students.

Keywords - Technology, Classrooms, Education, STEM, Physics. 


\section{Introduction}

Physics students of all ages often struggle conceptually with circuitry (Chang, Liu \& Chen, 1998; Liegeois, Chasseigne, Papin \& Mullet, 2003; Kollöffel \& de Jong, 2013). Despite being able to perform the calculations of rather advanced physics topics, many students still struggle with analyzing the simple circuit (Cohen, Eylon \& Ganiel, 1982). Concept development is an evolutionary process that humans undergo; this paper focuses on a way to provide this conceptual development in an innovative way (Garnett \& Treagust, 1992). The use of technology in the classroom can help students to better learn by improving their attitudes (Christensen, 1997). Furthermore, this allows for teachers to more efficiently instruct students on the topic at hand (Bitner \& Bitner, 2002).

The incorporation of technologies especially relevant today as more technology is available to students at younger ages than ever before. By integrating technology, specifically interactive systems into the classroom, students are pushed to become more "self-motivated learners and researchers" (Chacko, Appelbaum, Kim, Zhao \& Montclare, 2015). Those who are provided with access to interactive technology benefit from it by becoming more engaged with the material at hand, as discussed with the integration of apps and touch-screen technology in high school classrooms (Lewis, Zhao \& Montclare, 2012; Kim, Chacko, Zhao \& Montclare, 2014). Technology modules introduce a new teaching method that not only benefit students but also expose teachers to "current research" and modern teaching styles (Chan, Hom \& Montclare, 2011). Critical elements to the success of previous programs include "interactive experimentation and feedback-oriented design" (Chan et al., 2011; Lorenzini, Lewis \& Montclare, 2011).

In addition, "of all of the sciences in the US, physics continues to have the lowest representation of women" with women only earning " $21 \%$ of bachelor's degrees and $17 \%$ of $\mathrm{PhDs}$ in the field" (Ivie \& Tesfaye, 2012). While women do have careers in STEM fields, many women choose to leave their respective careers in STEM based upon "a discontent with science" (Mavriplis et al., 2011). Some leave their field due to a "lack of mentor or guidance" or that "science and engineering are unfriendly to women" (Mavriplis et al., 2011). The objective of this paper is to study the integration of an interactive, technology-rich module and its ability to further motivate and stimulate the interest of girls in high school physics.

As part of our continued collaboration with the Urban Assembly Institute of Mathematics and Science for Young Women (UAI) (Chan et al., 2011; Lorenzini et al., 2011; Lewis et al., 2012; Kim et al., 2014), we worked to increase students' interest and performance in physics. The 
teacher of the class was experienced having taught middle school science for one year and high school Physics for 3 years. In addition, he served as a mentor for the UAI students taking General Engineering 1003, an introduction to engineering course at the University. Three college students were selected as fellows responsible for developing and implementing a technology-rich module for the class. One of the fellows was a senior obtaining a bachelor of science (BS) and master of science (MS) in Computer Science. Throughout high school, he started and led a tutoring organization that created opportunities for students to visit and tutor in middle schools as well as leading boyscout troops. The second undergraduate fellow was a junior obtaining a BS in Biomolecular Science; he had experience as a private tutor for high school students in the areas of chemistry, biology, and mathematics for 3 years. The third student was a sophomore obtaining a BS in Chemistry and a BS in Chemical and Biomolecular Engineering. As a College Reading and Learning Association (CRLA) certified tutor, she tutored in the fields of math and science. She also organized the attendance and led coursework in computer programming courses for middle and high school students at a summer camp.

Approximately, 17 students in the high school physics class at UAI were randomly split into two groups: one control and one experimental group. The control group was compromised of 8 students, and the experimental group had a total of 9 students. All of the students were female, with $5.88 \%$ of the students of Middle Eastern descent, 11.76\% Hispanic, and 82.35\% African American. It is important to understand the diverse make up of the group so as to better understand how the electronic platform can help improve diversity in STEM. There is a "significant gap in mathematics and science scores between white students and those of black, Hispanic, and Native American students" in "Achievement test of precollege students" (Dix, 1987). "Under representation of these groups at the college level is the result both of their lower representation in higher education in general and of their distribution among fields" (Dix, 1987). Improving the overall experience and interest for these groups of students is important for the outreach of STEM fields.

\section{Design/methodology/approach}

The online system used was called Every Circuit (www.everycircuit.com/app) (Figure 1). It enabled students to build circuits in a virtual setting. Students could build series or parallel circuits by adding resistors to the system at their choosing. Additional settings could be added, such as a 
light bulb to be lit by the current, serving as an indicator of current flow. In addition, it displayed the current, voltage, and resistance in numerical values to better conceptualize it.

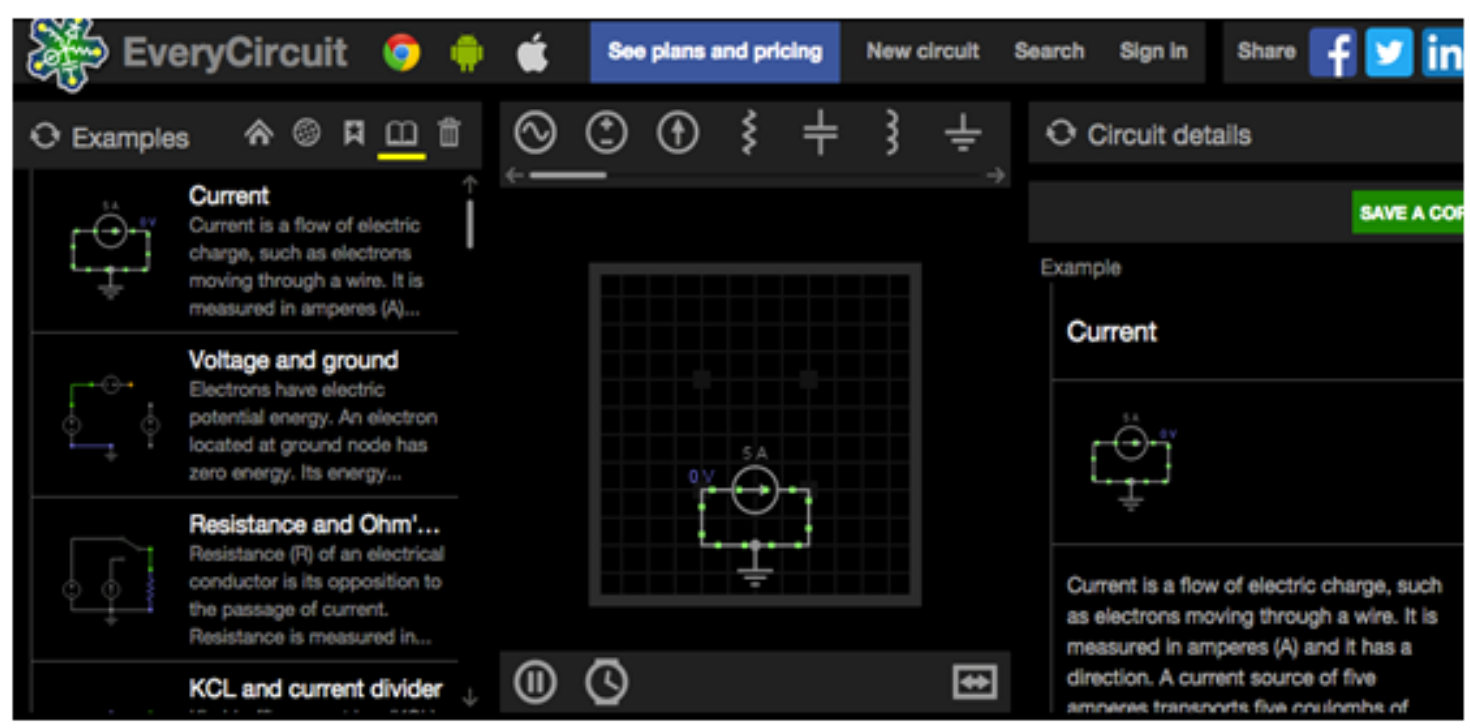

Figure 1. The Every Circuit home page for the online module used by the students

The online module enabled the students to virtually build and run circuits, as well as to observe how the current flowed through the circuit they built. The students used this system in an attempt to gain a conceptual understanding of both series and parallel circuits. A pre-quiz (Figure 2) was given to all of the students before they began to use the online module in order to test the knowledge of the students before providing help. The experimental group of students was then given step-by-step instructions on how to build a series circuit using the online module (Figure 3). These students were also provided questions to complete while building the circuit that focused on Ohm's Law. Then, the students were provided step-by-step instructions on how to build a parallel circuit using the online module (Figure 4). Another step-by-step handout was provided for designing the series circuits. The students in the control group were given almost identical packets to the experimental students; the control packets did not include instructions to the online module as they completed the entire lab on paper. Rather than being asked to build the respective circuits using the online module, they were provided pictures of the circuits in paper form. All students, regardless control or experimental, were asked identical questions and provided identical equation sheets (Figure 5). The students were then given a post-quiz (Figure 6) to determine how the system had helped them to better understand the topic of series circuits, 
parallel circuits, and Ohm's Law. The students were also asked to rank their experience using Every Circuit by filling out a survey (Figure 7).

\author{
Name: \\ Pre-Quiz "Circuits" \\ A student constructed a series circuit consisting of a 10.0-volt \\ battery, a 6.0-ohm lamp, and a resistor. The circuit does not \\ contain a voltmeter or an ammeter. When the circuit is operating \\ the total current through the circuit is 2.0 -ampere.
}

1. Please draw a diagram of the series circuit constructed to operate the lamp. Use an " $\mathrm{X}$ " to represent the lamp.

2. Moving 2.0 coulombs of charge through a circuit requires 24 joules of electric energy. What is the potential difference across the circuit?
a. $24 \mathrm{~V}$
b. $48 \mathrm{~V}$
c. $12 \mathrm{~V}$
d. $2.0 \mathrm{~V}$

3. Please draw a diagram of a parallel circuit with a $15-\mathrm{ohm}$ resistor, $\mathbf{R}_{1}$, and a 20 -ohm resistor, $\mathbf{R}_{2}$, connected to a 50 -volt source.

Figure 2. Pre-quiz given to the students before beginning 


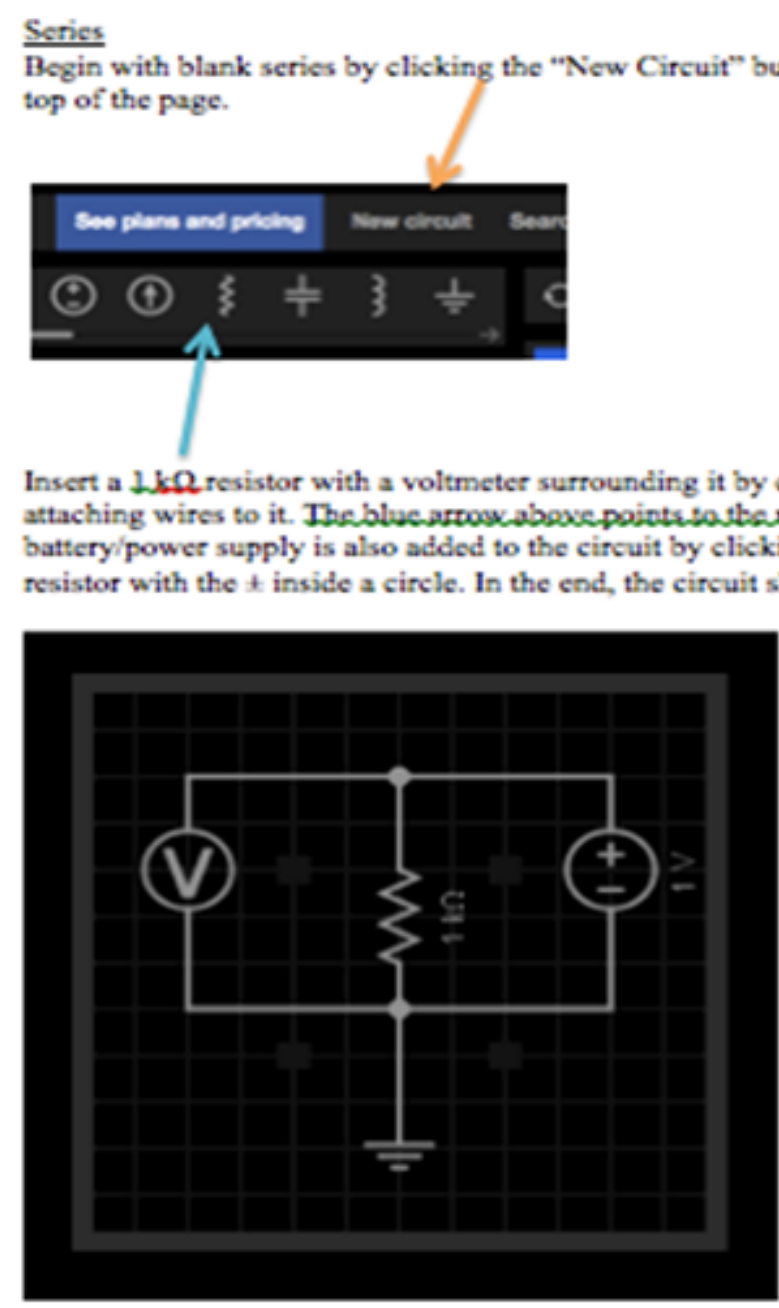

Press the run button on the bottom left of the circuit you just built.

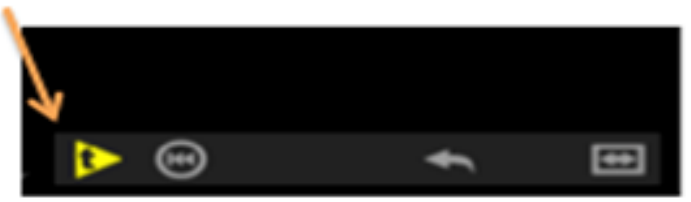

After pressing the run button, answer the following questions about what you see:

1. What is the value of the current (this is displayed beside the resistoe)?

2. What value does the voltmeter display? What other component of the series has the same value as the voltmeter?

These two values are the equivalent because the voltmeter is directly attached to both ends of the battery. It should read the entire voltage of the battery

Now, insert a second resistor in series with the first resistor. The second resistor should also have a value of $1 \mathrm{k} \Omega$. The voltmeter should only surround the first resistor of the series. 
The series should look like this after you've attached everything-

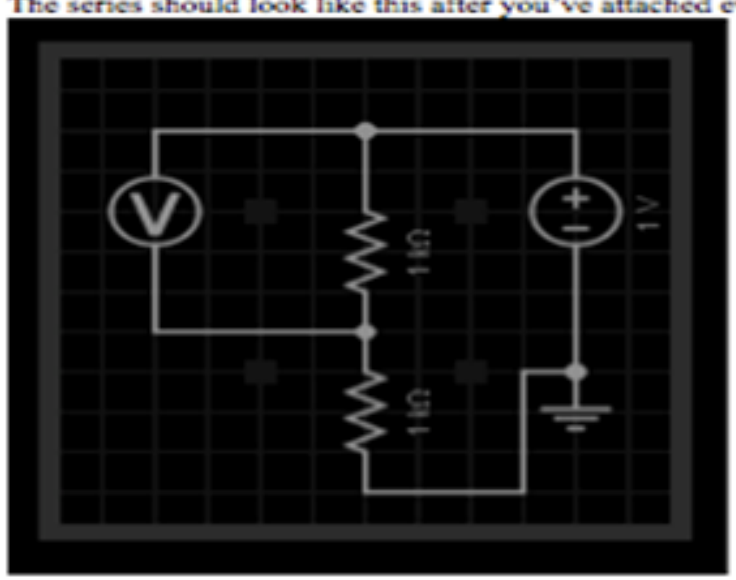

Again, press the run button and answer the following questions:

1. What is the voltage recorded by the voltmeter? Is it the same or different from the voltage of the battery?

2. What is the current through the first resistor? What is the current through the second resistor? What is the relationship between these values and the total current of the circuit?

You should have found that the currents are the same through each resistor and the total current, which is a key characteristic of resistors in series.

The individual voltage across one resistor is less than the total voltage provided by the battery. The total voltage (that of the battery) is the voltage of the first resistor added to the voltage of the second resistor. This is an application of Ohm's Law $\left(V_{r o r}-V_{1}+V_{2}\right)$.

Figure 3. Basic format given to all of the students for series circuits

\section{Paralel Crcuits}

Name:

Dase:

1. First, create the following circult diagram, connecting a voltage source to a lamp and a ground.

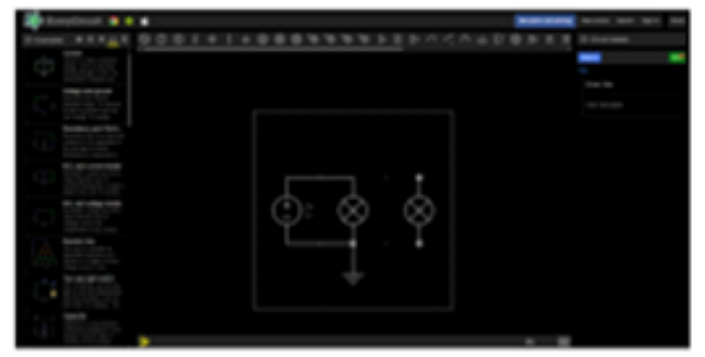


Make note of the voitages and amperages in the circuit.

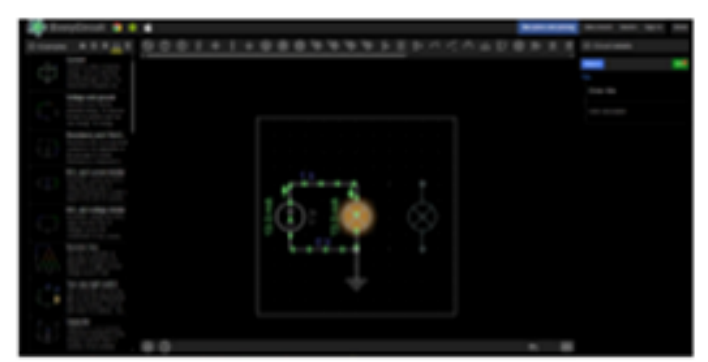

Votage:

Curfent (Amps): mA

2. Now, connest the second lebthuld to the cireuit in parallel with the first, with a switch between the first and second lightoulk, as displayed in the dagram below.

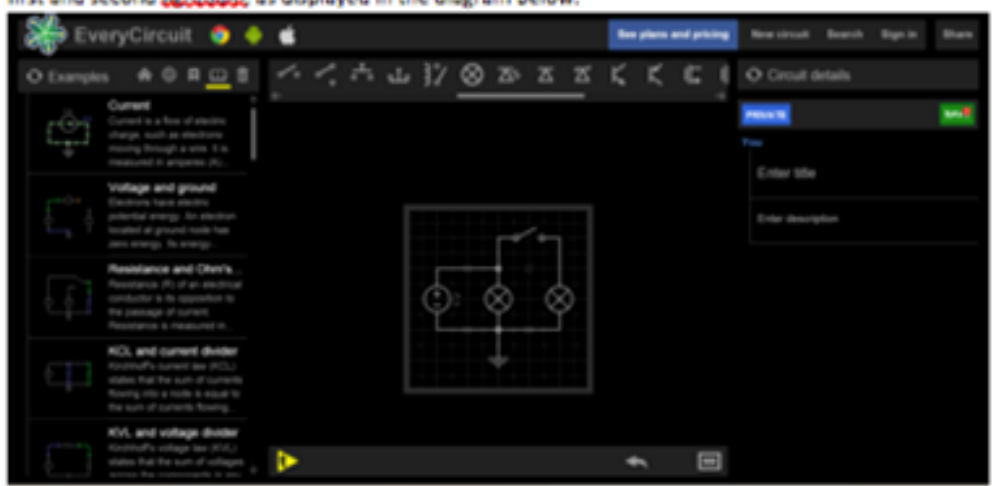

Now, run the circur. The curfent should run through the original circur and have the same current(mA) and voltage.

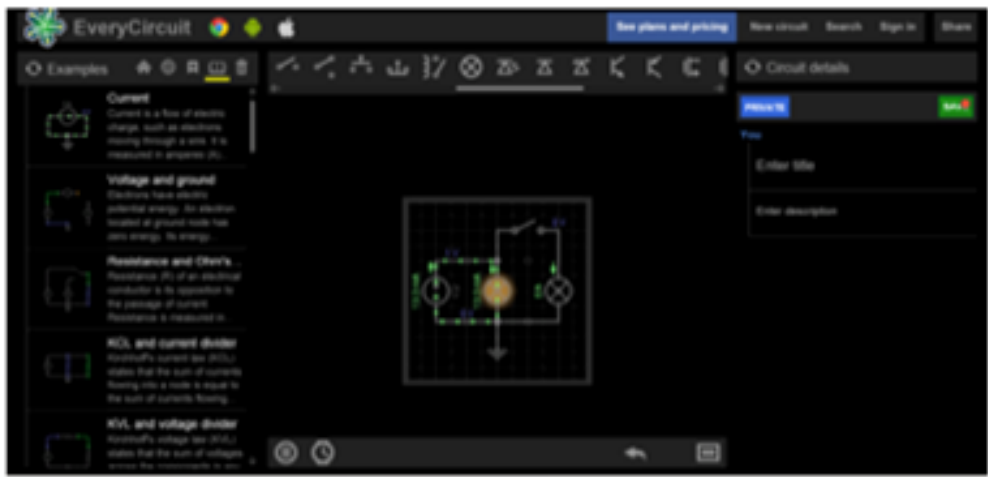

Now click on the switth you place between the first and second lightbulbs. This will close the circuit and cause the two lightbulbs to be connected to the voltage source in parallet. 


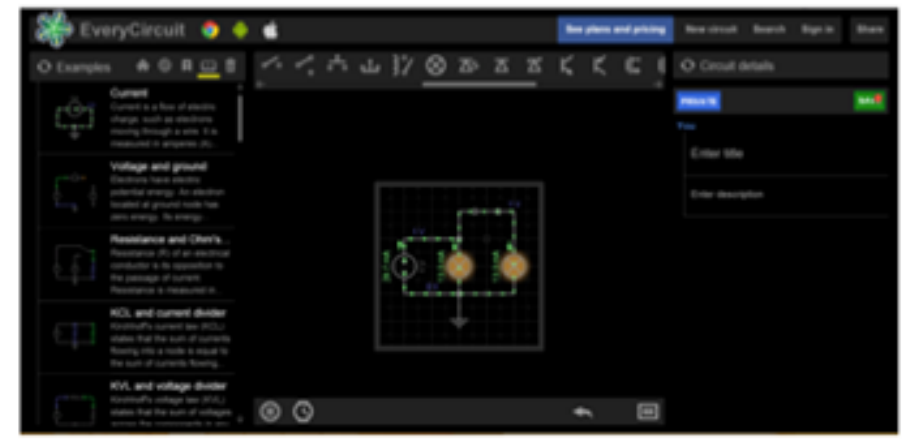

Make note of the voitage of the two branches and how it relates to the votage of the source.

\section{First Branch}

Votage: ___

Current (Amps): _ _ mA

Newly Connected Branch

Votage: ___ $\mathrm{v}$

Current (Amps): _ _ mA

whole Circuit

Votage: _

Current (Amps): $m A$

Vake note of the curfent of the two branches and tow this current relates to the curtent at the seurce.

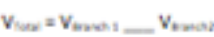

how - bonas - bond

3. Now, using three lamps design and draw a paralel circuit. Write down the currents and voltages for each branch and the rourse.

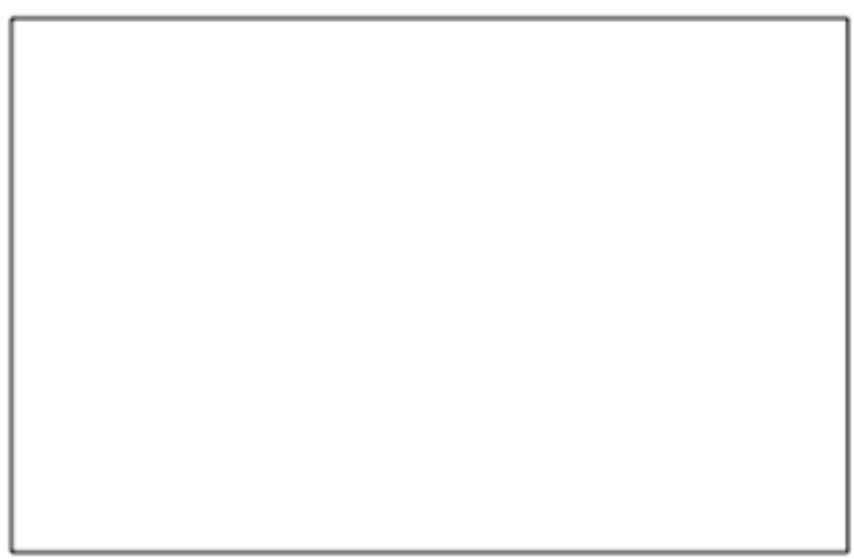

4. What relationships seem to be present?

- Between the total current ( $M A)$ and the current (mA) in each of the branches.

- Between the voltage in each branch.

Figure 4. Basic format given to all of the students for the parallel circuits 


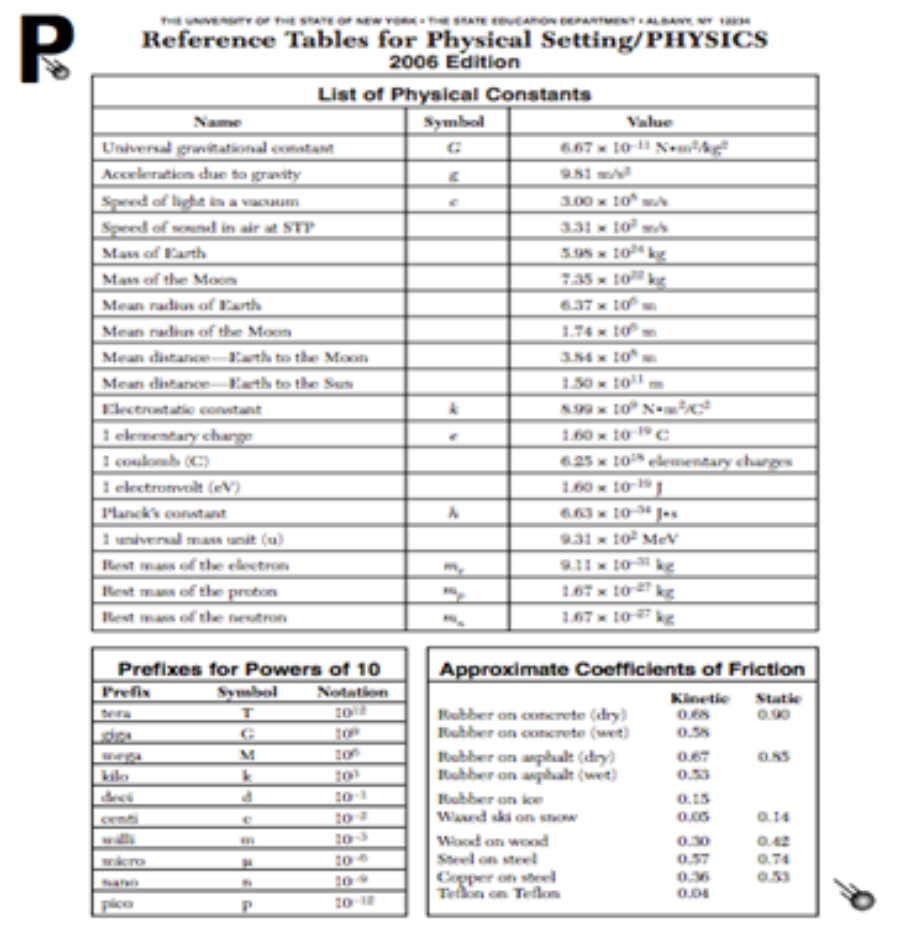

\begin{tabular}{|c|c|}
\hline \multicolumn{2}{|l|}{ Electricity } \\
\hline$F_{e}=\frac{k_{9} g_{2}}{r^{2}}$ & $\begin{array}{l}A \text { - enas sectional area } \\
E \text { - electine field strenghth }\end{array}$ \\
\hline$E-\frac{F_{1}}{4}$ & 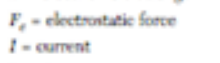 \\
\hline$v-\frac{w}{4}$ & $k$ - electratasis consten \\
\hline$I-\frac{\Delta g}{t}$ & $\begin{array}{l}L \text { - lenghth of cenduester } \\
P \text { - electrical power }\end{array}$ \\
\hline$\pi=\frac{y}{t}$ & $\begin{array}{l}4 \text { - chary } \\
\mathrm{A} \text { - menistance }\end{array}$ \\
\hline$n=\frac{d i t}{A}$ & 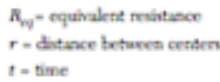 \\
\hline$P=\mathrm{V} I=t^{2} \mathrm{~N}=\frac{v^{2}}{\mathrm{~N}}$ & $\begin{array}{l}\text { V- potratid differsoce } \\
W \text { - work idhetricul energy) }\end{array}$ \\
\hline$W-N-V t=l^{2} R_{t}-\frac{V_{t}^{2}}{\bar{K}}$ & $\begin{array}{l}A \text { - chunge } \\
\rho \text { - raitikity }\end{array}$ \\
\hline Series Cireuats & Parallel Circuits \\
\hline$t-t_{1}-t_{2}-t_{3}=\ldots$ & $t=t_{1}+t_{2}+t_{3}+\ldots$ \\
\hline$v-v_{1}+v_{2}+v_{3}+\cdots$ & $v-v_{1}=v_{2}-v_{3}=\ldots$ \\
\hline$\pi_{n_{4}}=\pi_{1}+R_{2}-\pi_{3}+\ldots$ & $\frac{1}{K_{k_{\alpha}}}-\frac{1}{K_{1}}+\frac{1}{\mu_{2}}+\frac{1}{\mu_{3}}+\cdots$ \\
\hline
\end{tabular}

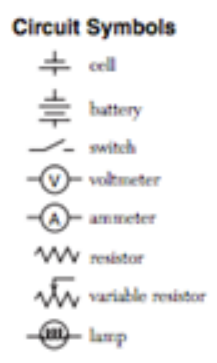

\begin{tabular}{|c|c|}
\hline \multicolumn{2}{|c|}{ Resistivities at $20^{\circ} \mathrm{C}$} \\
\hline Material & Renatuivity $(\Omega * x)$ \\
\hline Alumitum & $2.92 \times 10^{-3}$ \\
\hline Conper & $1.72 \times 10^{-5}$ \\
\hline Codd & $2.44 \times 10^{-5}$ \\
\hline Niktrome & $150 \times 10^{-3}$ \\
\hline Shither & $1.59 \times 10^{-4}$ \\
\hline Tungten & $5.60 \times 10^{-4}$ \\
\hline
\end{tabular}

Figure 5. Equation sheets that the students were allowed to use 
Name:

Post-Quiz "Circuits"

A $15.0-0 h m$ resistor and a $20.0-0 h m$ resistor are connected in parallel with a 9.0-volt battery. A single ammeter is connected to measure the total current of the circuit.

1. Draw a diagram of this circuit using. Use an " $\mathrm{A}$ " to represent the ammeter.

2. A 10-volt source has 4 resistors connected in series. The resistors are $2.0 \mathrm{ohms}, 5.0 \mathrm{ohms}, 9 \mathrm{ohms}$, and $4 \mathrm{ohms}$. What is the total current in the circuit?
a. $0.50 \mathrm{~A}$
b. $2.0 \mathrm{~A}$
c. $9 \mathrm{~A}$
d. $20 \mathrm{~A}$

3. Please draw a diagram of a series circuit with a $6.0-0 \mathrm{hm}$ resistor and a $12-\mathrm{ohm}$ resistor connected in parallel with a battery source.

Figure 6. Post-quiz given to the students after the lesson 
Name:

- On all scales, 1 being the lowest and 10 being the best.

On a scale of $1-10$, how much did you enjoy using this system?
$\begin{array}{lllllllll}2 & 3 & 4 & 5 & 6 & 7 & 8 & 9 & 10\end{array}$

On a scale of $1-10$, how well did you understand the topic before today?

$\begin{array}{llllllllll}1 & 2 & 3 & 4 & 5 & 6 & 7 & 8 & 9 & 10\end{array}$

Did the system help you to better understand the topic?

YES

NO

If YES, on a scale of 1-10 how well do you feel you know the topic at hand (Circuits) now.

$\begin{array}{llllllllll}1 & 2 & 3 & 4 & 5 & 6 & 7 & 8 & 9 & 10\end{array}$

On a scale of $1-10$, how easy was it to operate the system?

$\begin{array}{llllllllll}1 & 2 & 3 & 4 & 5 & 6 & 7 & 8 & 9 & 10\end{array}$

Did you enjoy using the system more than the other systems used previously in this class?

YES

NO

On a scale of 1-10, how much do you normally enjoy using the other systems?

$\begin{array}{llllllllll}1 & 2 & 3 & 4 & 5 & 6 & 7 & 8 & 9 & 10\end{array}$

Figure 7. Surveys given to the students after the post-quiz was completed

\section{Results}

The pre-quiz was able to determine that both the experimental and control group had nearly identical knowledge base with scores of $70.37 \%$ and $70.83 \%$, respectively (Figure 8 ). This was improved after using the online module when the experimental group outperformed the control group. The experimental group scored $70.37 \%$ overall while the control group demonstrated lower performance as demonstrated by the $66.67 \%$ score (Figure 9). 


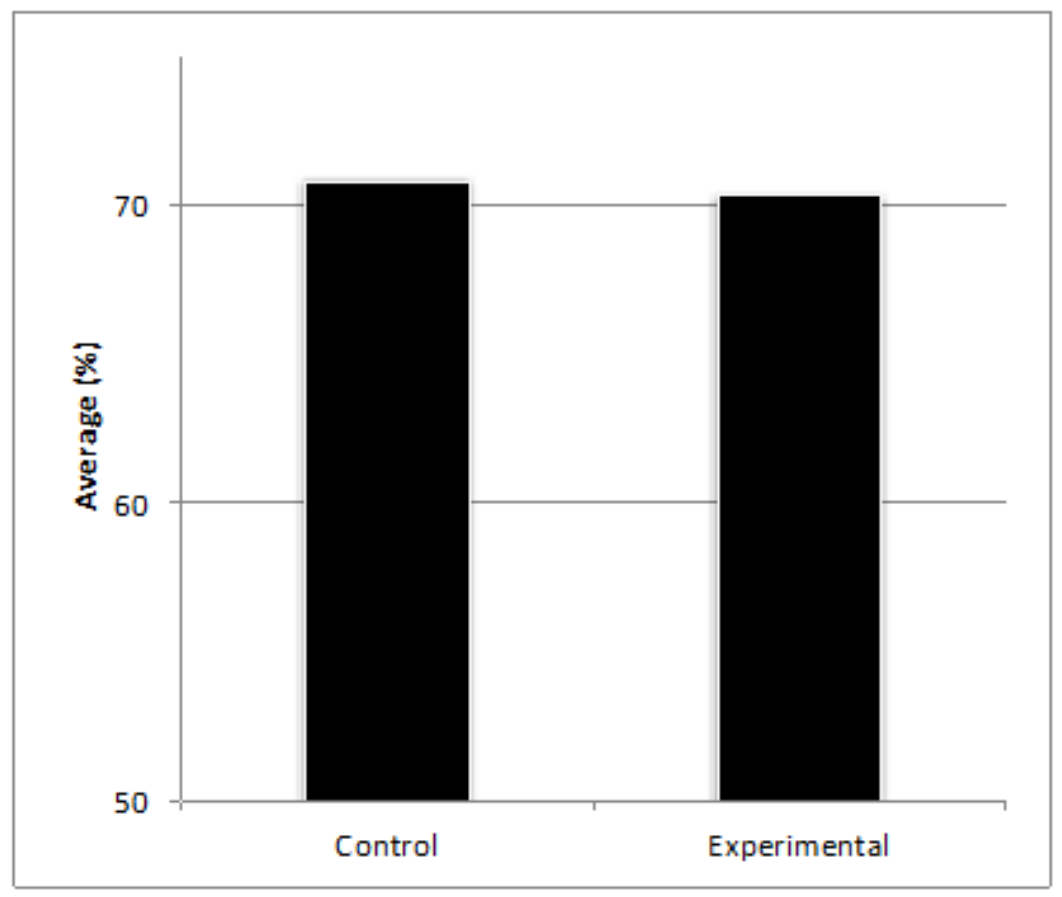

Figure 8. The overall averages for both the control and experimental group for the pre-quizzes

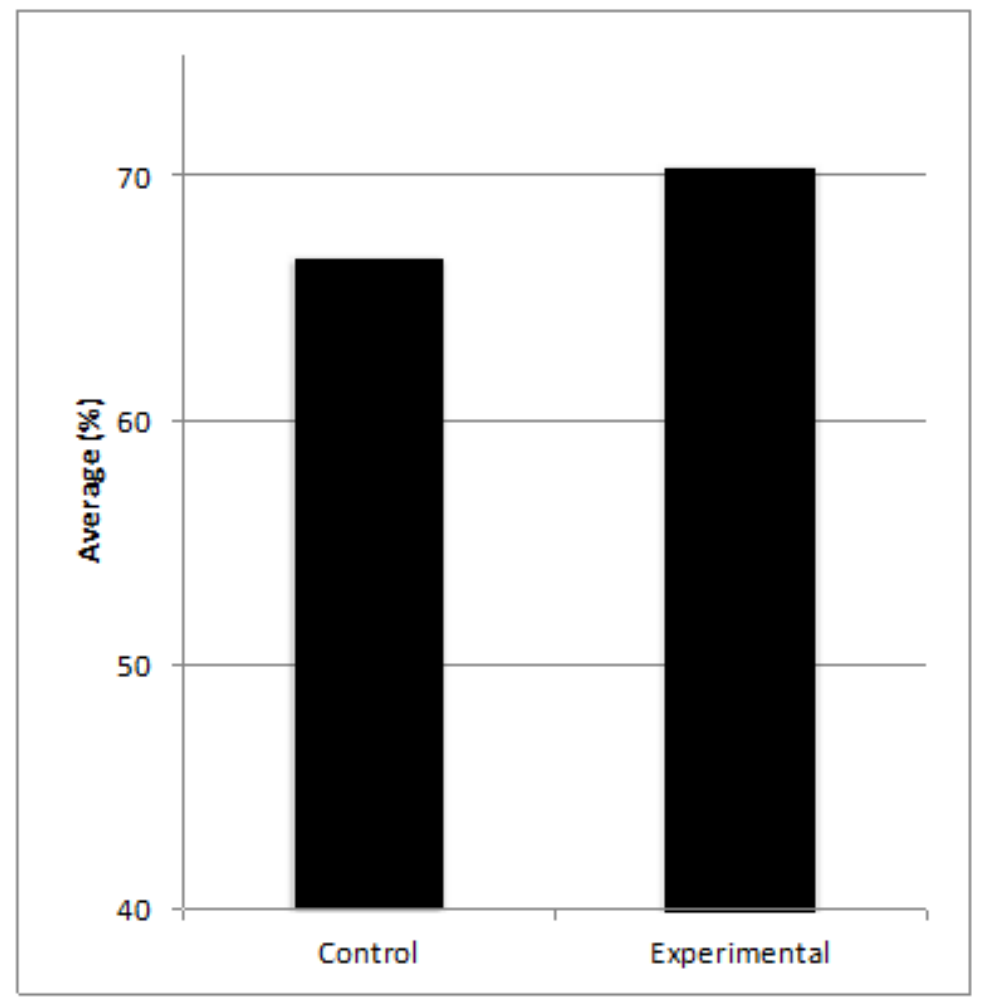

Figure 9. The overall averages for both the control and experimental groups for the post-quizzes 
The online module did, in fact, help the experimental group in drawing circuits. The experimental group scored $77.78 \%$ on the pre-quiz, however they then scored $88.89 \%$ on the post-quiz question concerning series circuit (Figure 10). The control group also showed improvement on the series question; they improved from a $75.00 \%$ to a $100.00 \%$ (Figure 11). On the question concerning drawing a parallel circuit, the experimental group scored a $66.67 \%$ on the pre-quiz and a $77.78 \%$ on the post-quiz question (Figure 12). The control group performed worse on the post-quiz question concerning drawing a parallel circuit than on the pre-quiz concerning the same type of question. The control group went from a $62.50 \%$ to a $75.00 \%$ average on the question (Figure 13). This shows that the lesson allowed for improvement on the series and parallel questions for both groups. The online platform allowed for the students to better comprehend how to draw parallel and series diagrams than they were able to do beforehand.

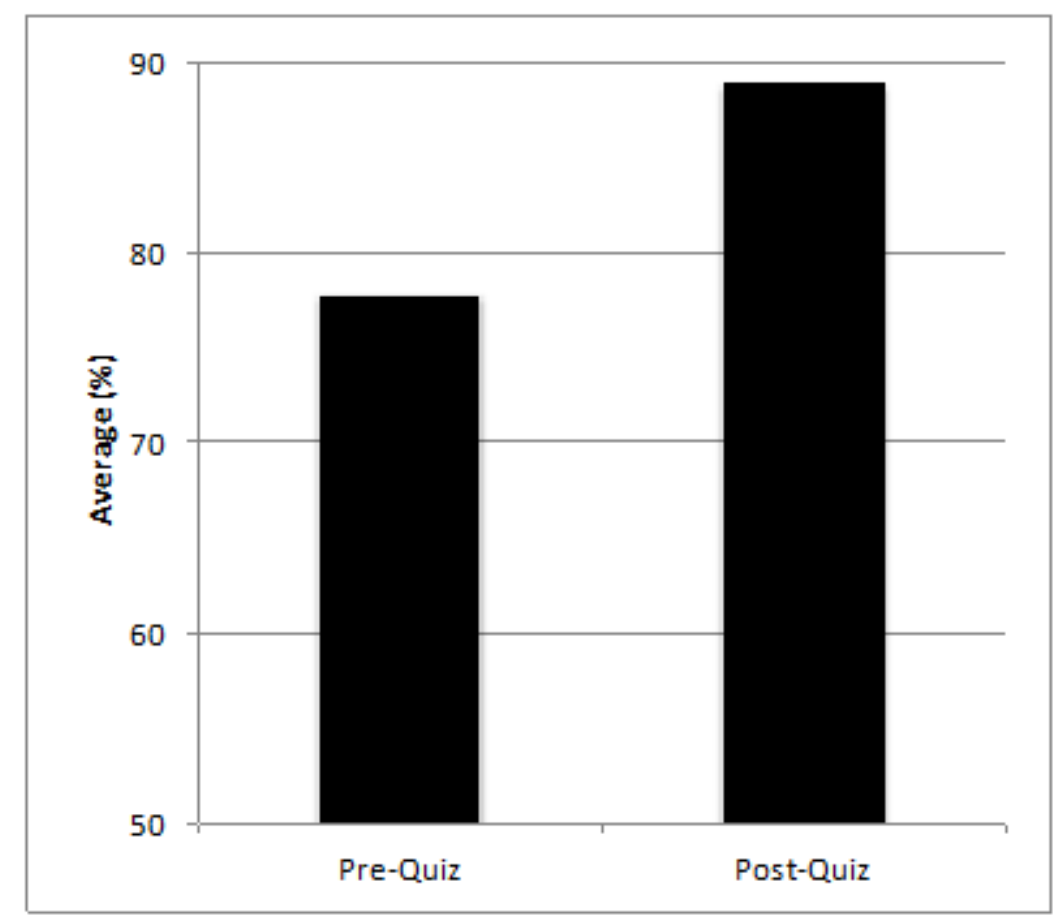

Figure 10. The overall averages for the question for drawing a series circuit for the experimental group 


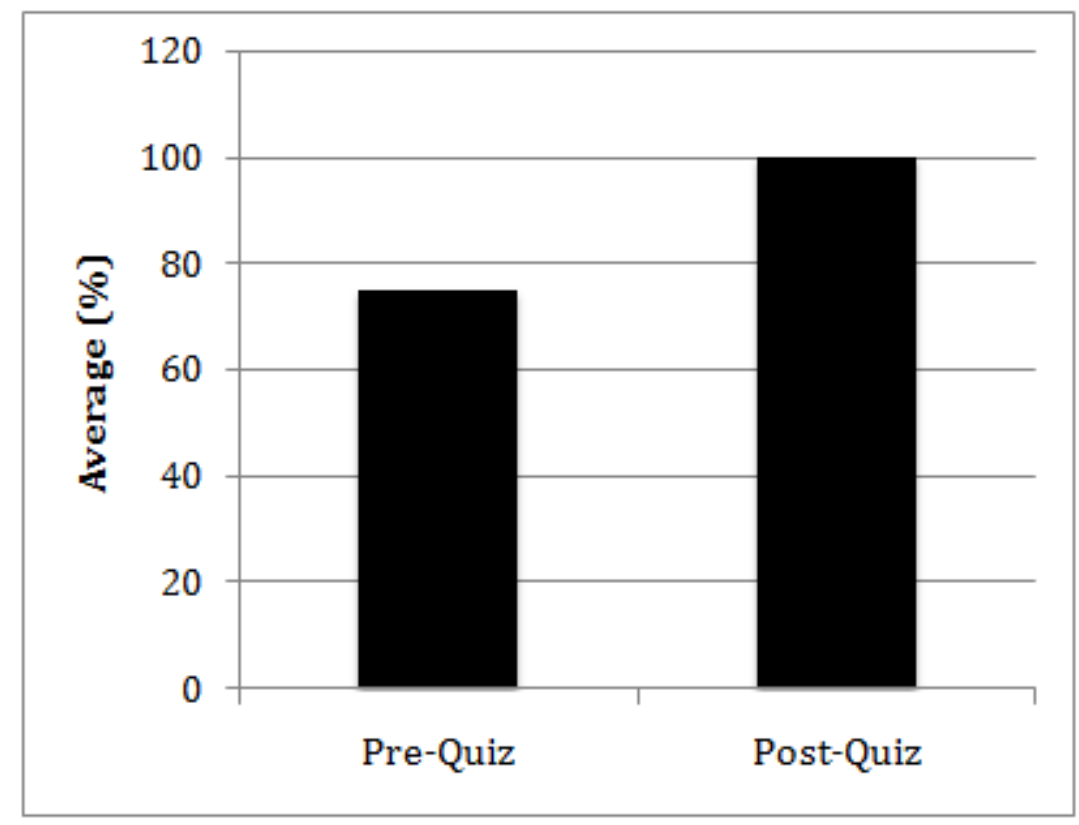

Figure 11. The overall average for the control group for the question regarding drawing a series diagram

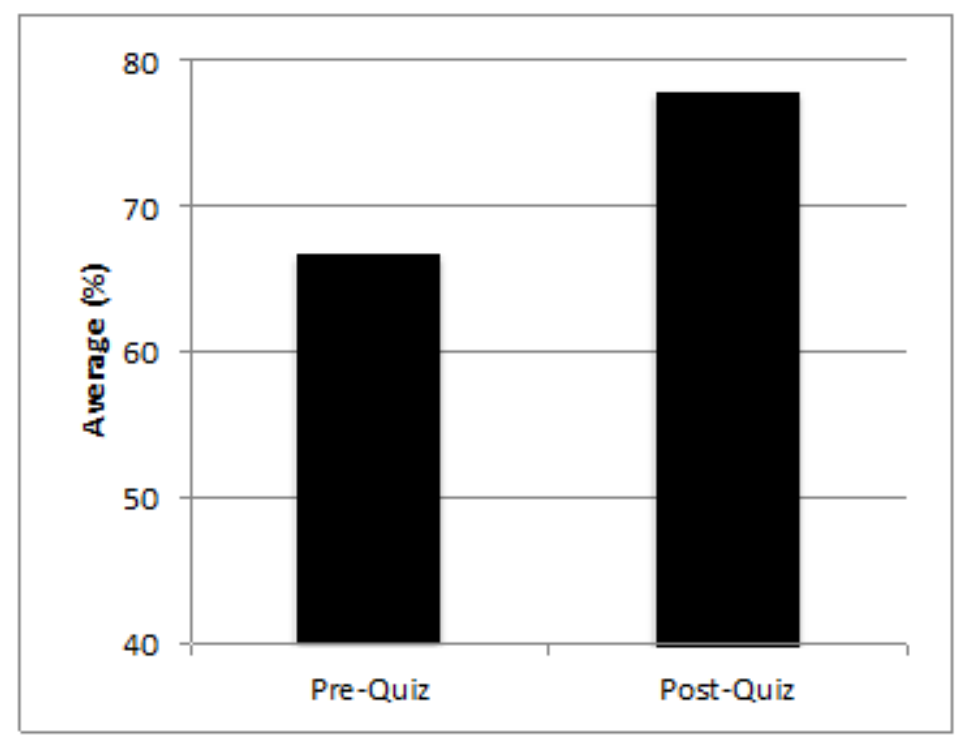

Figure 12. The overall average for the experimental group for the question regarding drawing a parallel diagram 


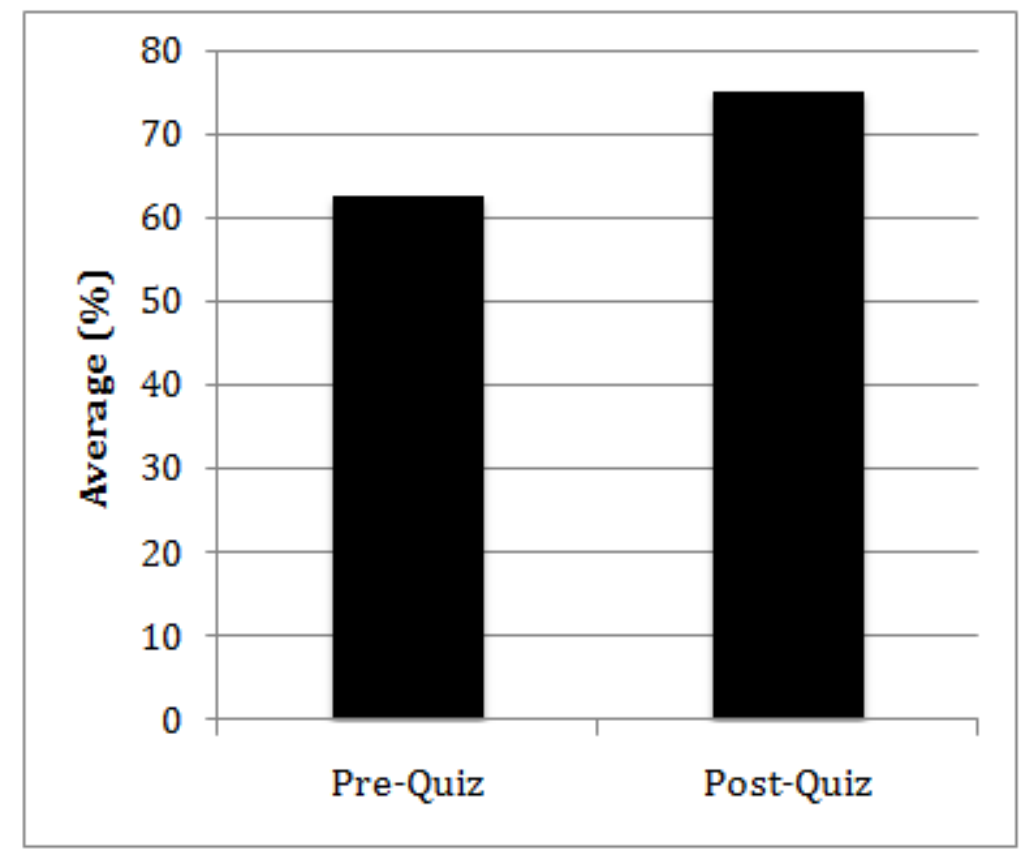

Figure 13. The overall average for the control group for the question regarding drawing a parallel diagram

Students were given a survey to find out about the technology from their perspective (Figure 14). Upon rating their experiences using the system, the experimental group rated how much they enjoyed using the system on a scale of 1-10 with 1 being the least enjoyable and 10 being the most enjoyable. Out of a total of 9 responses, 3 of the students ranked it a 7, 3 of the students ranked it an 8, and 3 of the students ranked it a 9 (Figure 15). This affirmed that the students did find using the online system highly engaging. 
Name:

- On all scales, 1 being the lowest and 10 being the best.

On a scale of $1-10$, how much did you enjoy using this system?

$\begin{array}{llllllllll}1 & 2 & 3 & 4 & 5 & 6 & 7 & 8 & 9 & 10\end{array}$

On a scale of 1-10, how well did you understand the topic before today?

$\begin{array}{llllllllll}1 & 2 & 3 & 4 & 5 & 6 & 7 & 8 & 9 & 10\end{array}$

Did the system help you to better understand the topic?

$$
\text { YES NO }
$$

If YES, on a scale of 1-10 how well do you feel you know the topic at hand (Circuits) new,

$$
\begin{array}{llllllllll}
1 & 2 & 3 & 4 & 5 & 6 & 7 & 8 & 9 & 10
\end{array}
$$

On a scale of $1-10$, how easy was it to operate the system?
12
34
6
$\begin{array}{llll}7 & 8 & 9 & 10\end{array}$

Did you enjoy using the system more than the other systems used previously in this class?

YES NO

On a scale of $1-10$, how much do you normally enjoy using the other systems?

$\begin{array}{llllllllll}1 & 2 & 3 & 4 & 5 & 6 & 7 & 8 & 9 & 10\end{array}$

Figure 14. Surveys given to the students after the post-quiz was completed

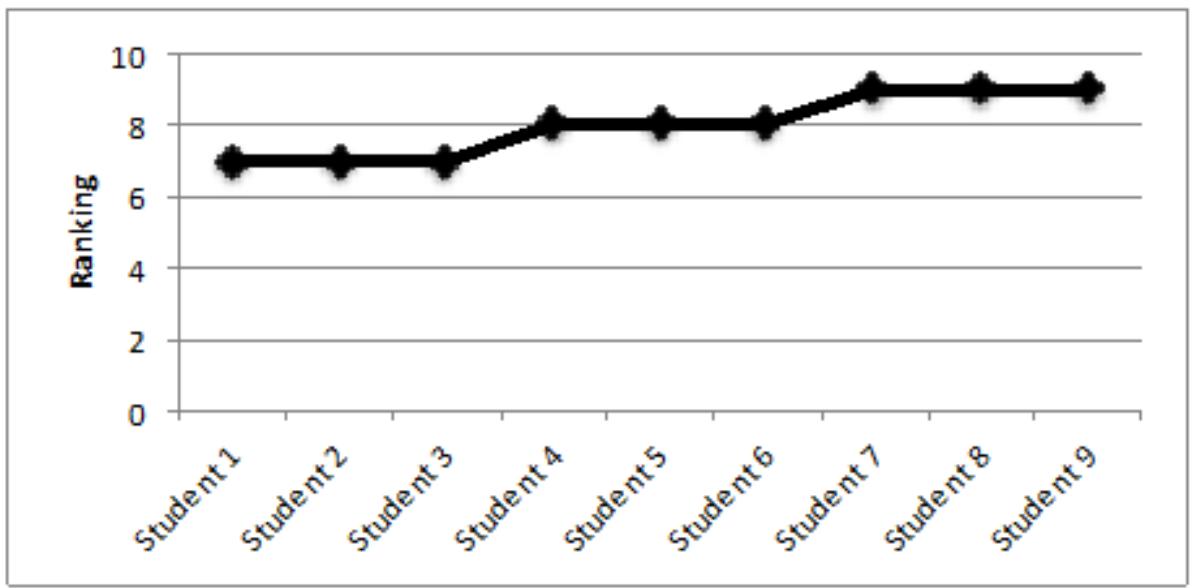

Figure 15. Ranking how much the students enjoyed using the system on a scale of 1-10 
Students also were asked to answer "Yes" or "No" to see if the system better helped them understand the topic at hand. Of the 9 students, $77.78 \%$ of the students responded that it did help them, $11.11 \%$ responded that it did not, and $11.11 \%$ did not reply to this question (Figure 16). This demonstrated that the students improved their understanding by using the system..

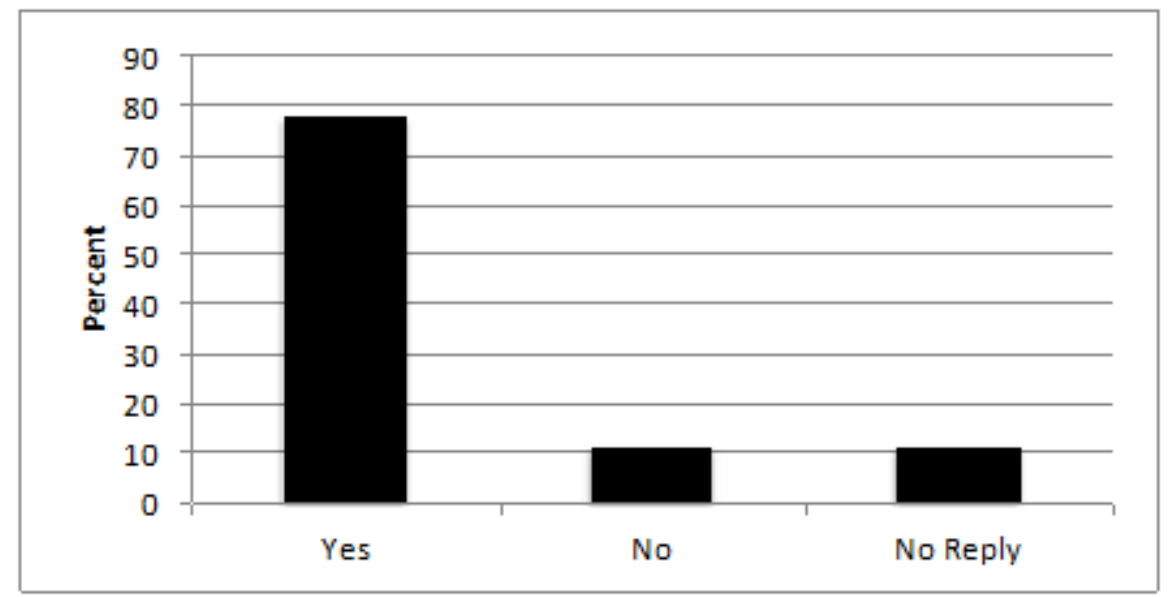

Figure 16. Responses to see if the students understood the topic better than before the experimental run

Their teacher was also given a survey to find out more about the technology from his perspective (Figure 17). He found that the technology was easy for his students to use. He also expressed that the site was straightforward; there was little to no disruptions with the learning occurring due to the technology. Overall, he affirmed that the experimental group was more engaged than the control group. 


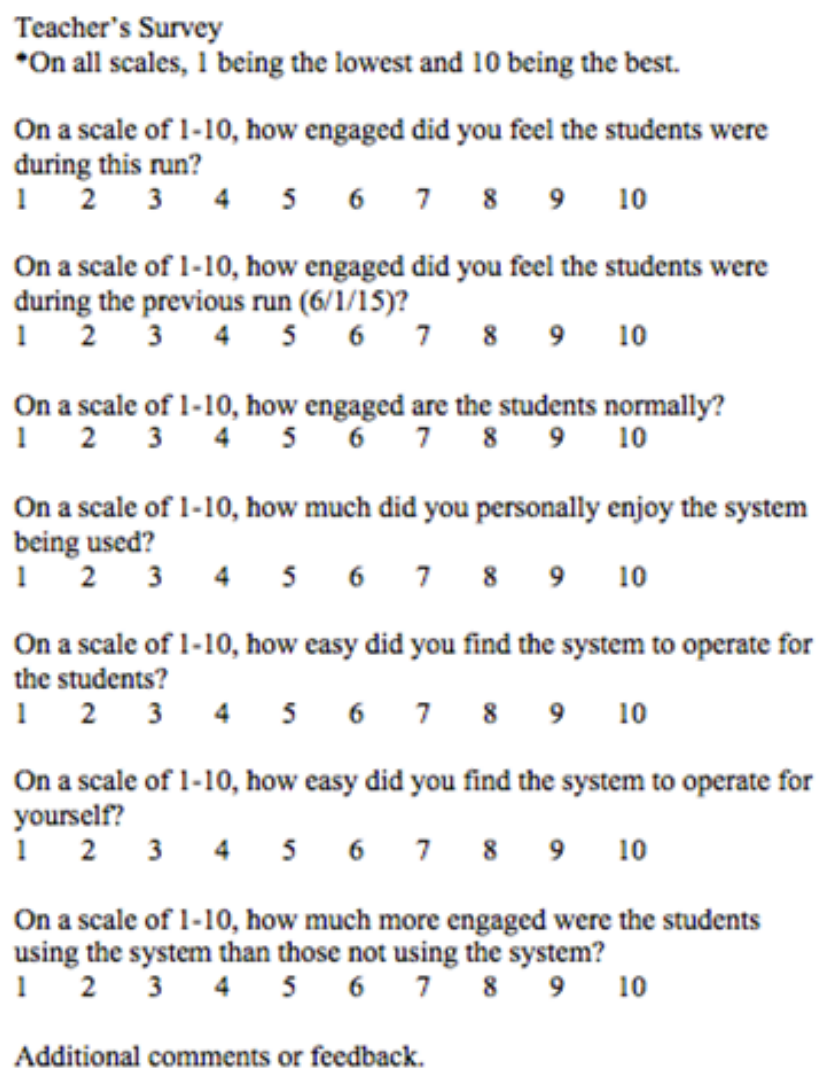

Figure 17. Survey given to the teacher

\section{Conclusions}

At first, the students using the Every Circuit had to get familiar with using the system. The control group students using the paper copies seemed to have a better understanding initially. However, once the students felt comfortable using the system, they seemed to both understand and enjoy the circuitry lessons more than those using the paper format. An issue in attempting to use Every Circuit arose when students were connecting the circuits. This was addressed by providing a brief explanation on where to click on the screen to connect the circuits. Once addressed, the students were engaged with Every Circuit, especially the ability to virtually turn on a light bulb. This helped the students to know when the circuit did and did not work. The implementation of virtual circuit building through Every Circuit assisted the students in learning the material by further engaging them. As illustrated, a significant amount of students agreed that the technology helped them better understand circuits. They were, overall, more interested in the topic once technology was added.

After the pre-quiz, the college students provided a brief introduction to the topic at hand. One mentor discussed circuits in series, and the other discussed circuits in parallel. This provided 
valuable teaching experience for both mentors. Additionally, the two college mentors circled the classroom troubleshooting any issues or questions that arose, such as the aforementioned connection tissue. This allowed the mentors one-on-one time with the students and develop a more personal relationship with them.

In assisting students to better understand the concepts, the teacher was able to have more time interacting with the students. The module gave the teacher the ability to focus on answering the student rather than splitting his time between the individual and the entire classroom simultaneously. The teacher and the college mentors were free to go around the classroom to answer any individual question the students might have. Thereby, the teacher was permitted time to address individual needs of students, rather than addressing the entire class. This led to more personalized interactions and maximized the teacher's involvement. Due to the virtual light bulb provided by the Every Circuit, students could correct their own mistakes and self-learn better than those simply attempting it on paper. The light bulb would either not light up, light up, or have too much light enabling students to see if their circuit was running properly. The use of a virtual light bulb also demonstrated the presence of physics in everyday situations; "incorporating elements of everyday life" allowed the UAI students to decompartmentalize their school and home lives.

A crucial challenge in teaching students about circuits is conceptual understanding. By employing Every Circuit, students' proficiency in illustrating circuits is also increased. This illustrates that the students obtained a better conceptual understanding of circuits due to the addition of technology. This work is in agreement with the previous studies of employing touch-screen technology.

\section{Program Outcomes}

The use of technology in the high school setting of UAI proved to be beneficial for all. Every Circuit was simple for the students and teacher to use and readily incorporated into the classroom. There was an overall improvement of understanding by the students in regards to how to properly make both a series and parallel circuit, directly correlated to their use of the system. The ease of use made a direct impact in helping the students to understand how to build the circuits. Based on the quiz performance and survey assessments, the students took an interest in using the system while also improving their knowledge of how a circuit works. The system 
permitted the teacher to further his relationship one-on-one with students, and the implementation of the technology allowed college mentors to sample teaching a lesson.

\section{Acknowledgements}

This work was supported by the NSF MRSEC Program under award number DMR-1420073 and NSF DMR-1505214. We thank Hassan Mojtabaeezamani from the Urban Assembly Institute of Math and Science for Young Women and In School Apps for their help and contribution to this work.

\section{References}

Bitner, N., \& Bitner, J. (2002). Integrating Technology into the Classroom: Eight Keys to Success. Journal of Technology and Teacher Education, 10(2), 95-100.

Chacko, P., Appelbaum, S., Kim, H., Zhao, J., \& Montclare, J,K. (2015). Integrating technology in STEM education. Journal of Technology and Science Education, 5(1), 5-14.

http://dx.doi.org/10.3926/jotse.124

Chan, Y.M., Hom, W., \& Montclare, J.K. (2011). Mentored Chem-Bio Technology Lab to Promote Early Interest in Science. Journal of Chemical Eduation, 88(6), 751-754. http://dx.doi.org/10.1021/ed100476e

Chang, K.-E., Liu, S.-H., \& Chen, S.W. (1998). A testing system for diagnosing misconceptions in DC electric circuits. Computers and Education, 31(2), 195-210. http://dx.doi.org/10.1016/S0360$1315(98) 00030-\mathrm{X}$

Christensen, R. (1997). Effect of technology integration education on the attitudes of teachers and their students. Journal of Research on Technology in Education, 34(4), 411-433.

http://dx.doi.org/10.1080/15391523.2002.10782359

Cohen, R., Eylon, B., \& Ganiel, U. (1983). Potential difference and current in simple electric circuits: A study of students' concepts. American Journal of Physics, 51(5), 407-412. http://dx.doi.org/10.1119/1.13226

Dix, L.S. (1987). Minorities: Their Underrepresentation and Career Differentials in Science and Engineering. Washington, D.C.; National Academy Press. 
Garnett, P., \& Treagust, D. (1992). Conceptual Difficulties Experienced by Senior High School Students of Electrochemistry: Electric Circuits and Oxidation Reduction Equations. Journal of Research in Science Teaching, 29(2), 121-142. http://dx.doi.org/10.1002/tea.3660290204

Ivie, R., \& Tesfaye, C.L. (2012). Women in physics: A tale of limits. American Institute of Physics, 65(2), 47. http://dx.doi.org/10.1063/pt.3.1439

Kim, H., Chacko, P., Zhao, J., \& Montclare, J.K. (2014). Using Touch-Screen Technology, Apps, and Blogs To Engage and Sustain High School Students' Interest in Chemistry Topics. Journal of Chemical Education, 91(11), 1818-1822. http://dx.doi.org/10.1021/ed500234z

Kollöffel, B., \& de Jong, T. (2013). Conceptual understanding of electrical circuits in secondary vocational engineering education: Combining traditional instruction with inquiry learning in a virtual lab. Journal of Engineering Education, 102(3), 375-393. http://dx.doi.org/10.1002/jee.20022

Lewis, M.S., Zhao, J., \& Montclare, J.K. (2012). Development and Implementation of High School Chemistry Modules using Touch-Screen Technologies. Journal of Chemical Education, 89(8), 1012-1018. http://dx.doi.org/10.1021/ed200484n

Liegeois, L., Chasseigne, G., Papin, S., \& Mullet, E. (2003). Improving high school students' understanding of potential difference in simple electric circuits. International Journal of Science Education, 25(9), 1129-1145. http://dx.doi.org/10.1080/0950069022000017324

Lorenzini, R., Lewis, M.S., \& Montclare, J.K. (2011). College-Mentored Polymer/Materials Science Modules for Middle and High School Students. Journal of Chemical Education, 88(8), 1105-1108. http://dx.doi.org/10.1021/ed1005618

Mavriplis, C., Heller, R., Beil, C., Dam, K., Yassinskaya, N., Shaw, M., et al. (2011). Mind the Gap: Women in STEM Career Breaks. Journal of Technology Management \& Innovation, 5(1).

Published by OmniaScience (www.omniascience.com)

Journal of Technology and Science Education, 2016 (www.jotse.org)

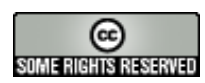

Article's contents are provided on an Attribution-Non Commercial 3.0 Creative commons license. Readers are allowed to copy, distribute and communicate article's contents, provided the author's and JOTSE journal's names are included. It must not be used for commercial purposes. To see the complete licence contents, please visit http://creativecommons.org/licenses/by-nc/3.0/es/ 